\title{
New Concepts for High-Intensity PV Modules for Use with Dish Concentrator Systems
}

J.S. Ward, A. Duda, T.J. Coutts, and S.R. Kurtz National Renewable Energy Laboratory

Presented at the 15th Photovoltaics Program Review Meeting Lakewood, Colorado

September 15, 1998

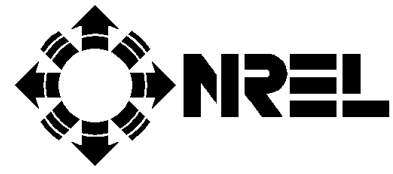

National Renewable Energy Laboratory 1617 Cole Boulevard Golden, Colorado 80401-3393

A national laboratory of the U.S. Department of Energy Managed by Midwest Research Institute for the U.S. Department of Energy under contract No. DE-AC36-83CH10093

Work performed under task number 5200.2000

October 1998 


\begin{abstract}
NOTICE
This report was prepared as an account of work sponsored by an agency of the United States government. Neither the United States government nor any agency thereof, nor any of their employees, makes any warranty, express or implied, or assumes any legal liability or responsibility for the accuracy, completeness, or usefulness of any information, apparatus, product, or process disclosed, or represents that its use would not infringe privately owned rights. Reference herein to any specific commercial product, process, or service by trade name, trademark, manufacturer, or otherwise does not necessarily constitute or imply its endorsement, recommendation, or favoring by the United States government or any agency thereof. The views and opinions of authors expressed herein do not necessarily state or reflect those of the United States government or any agency thereof.
\end{abstract}

Available to DOE and DOE contractors from:

Office of Scientific and Technical Information (OSTI)

P.O. Box 62

Oak Ridge, TN 37831

Prices available by calling 423-576-8401

Available to the public from:

National Technical Information Service (NTIS)

U.S. Department of Commerce

5285 Port Royal Road

Springfield, VA 22161

703-605-6000 or 800-553-6847

or

DOE Information Bridge

http://www.doe.gov/bridge/home.html 


\title{
New Concepts for High-Intensity PV Modules for Use with Dish Concentrator Systems
}

\author{
J. S. Ward, A. Duda, T. J. Coutts, and S. R. Kurtz \\ National Renewable Energy Laboratory (NREL) \\ 1617 Cole Blvd., Golden CO, 80401 USA
}

\begin{abstract}
In this paper we report on our efforts to fabricate monolithically interconnected modules (MIMs) from GaAs device structures. The small size of the component cells comprising the MIM allows for operation at very high flux densities. This relaxes the requirement for a small spotsize to be generated by the optics. The devices are grown on semi-insulating substrates, allowing the incorporation of an extremely efficient back surface reflector (BSR). This BSR is an effective tool for thermal management of the array. The possibility of using this device configuration in conjuction with the large dish concentrators developed by the solar thermal community is examined. The advantages of using multijunction devices for this application is also discussed.
\end{abstract}

\section{INTRODUCTION}

Most attempts to use photovoltaics for solar energy conversion using concentrated sunlight have involved very small devices and Fresnel lenses. While interesting work has taken place using this approach, it is difficult to attain very high $(>500 \mathrm{x})$ concentration ratios with this technology. The last decade has seen impressive progress in the state of the art for high-efficiency III-V devices. GaAs-based multijunction devices are now entering production for space power applications. These devices have demonstrated efficiencies in excess of $30 \%$ under the simulated direct solar spectrum (1). This level of performance makes them attractive candidates for use in terrestrial concentrator systems. However, the costs involved in manufacturing these devices require that they operate under very high concentration for them to play a useful role in terrestrial power generation.

In the late 1980s, studies were undertaken to ascertain the potential of various concentrator technologies. The consensus at that point was that refractive optics in the form of Fresnel lenses held the most promise, and that reflective optics such as dishes and heliostats would probably not be useful. While this conclusion may have been valid in the late 1980s, recent advances in dish technology, active cooling systems, and device configuration argue in favor of revisiting this issue. The challenges remain, but evolution of all the component technologies has come a long way toward addressing these challenges. The primary focus of this paper is to describe a device design originally developed for thermophotovoltaic (TPV) applications that could offer solutions to some of the challenges to making PV a viable option for use in dish concentrator systems. 


\section{MONOLITHICALLY INTEGRATED MODULES}

Monolithic integration of photovoltaic devices is a concept that is over 20 years old. In 1975, monolithic integration of silicon devices was described (2). In 1980, Bordon described a scheme for monolithic integration of $\mathrm{AlGaAs} / \mathrm{GaAs}$ concentrator cells (3). It was recognized as a strategy for dealing with the high current densities generated under concentration. Many small devices, connected in series, will limit the current to that which is generated within a single component cell, while the voltages are additive. GaInAs devices, using an identical interconnect scheme, were demonstrated by the Spire Corporation in 1994 as receivers for laser power beaming (4). Soon thereafter, researchers at NASA began looking at these devices as potential TPV converters. These devices have been referred to as monolithically integrated modules (MIMs) (5). The use of the semi-insulating substrates facilitates the incorporation of an extremely efficient back surface reflector (BSR). BSRs have been in use for over 30 years as a means of thermal management for cells used in space power systems (6). Here, the BSR acts as the spectral control device sending sub-bandgap photons back to the heat source. Thereforc, this single solid-state device incorporates two of the essential elements of a TPV system. A variant of this approach was developed at NREL begining in 1995. The NREL design uses interdigitation and a novel scheme that employs the grid fingers of the component cells as the interconnect structure (7). These features allow the devices to operate at extremely high current densities and increase the flexibility of the output parameters. Figure 1 is a simplified plan view of this design. It includes just two sub-cells for clarity. Most designs are composed of many more. Indeed, the number of sub-cells per unit length is an adjustable parameter that allows one to determine the output voltage of the device because, in series, the voltages are additive. Figure $\mathbf{2}$ is a scanning electron micrograph (SEM) image of the grid finger interconnect structure.

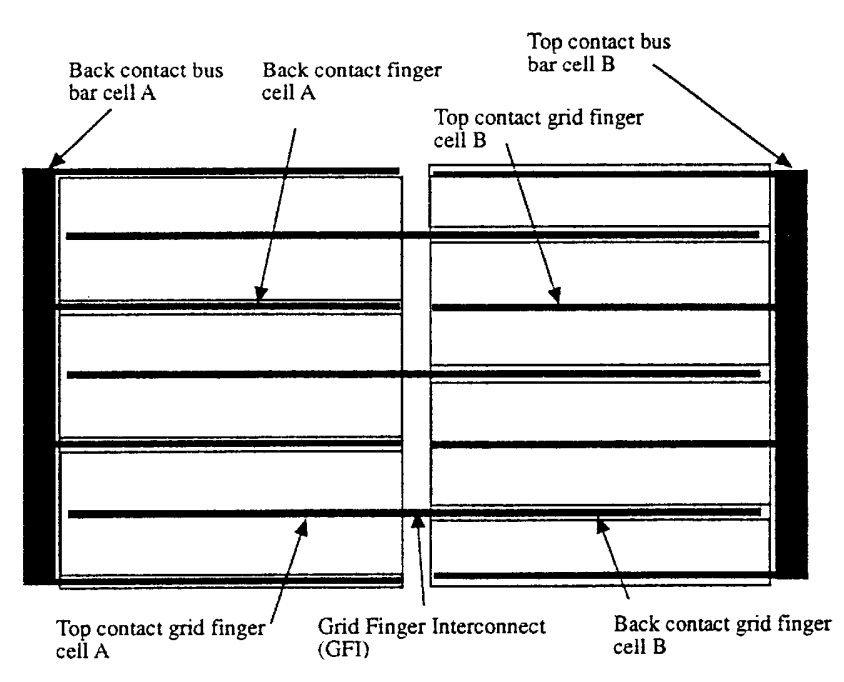

FIGURE 1: Simplified plan view of interdigitated, grid finger interconnected device. Only two component sub-cells are shown for clarity. Typical MIMs may consist of an arbitrarily large number of subcells. 


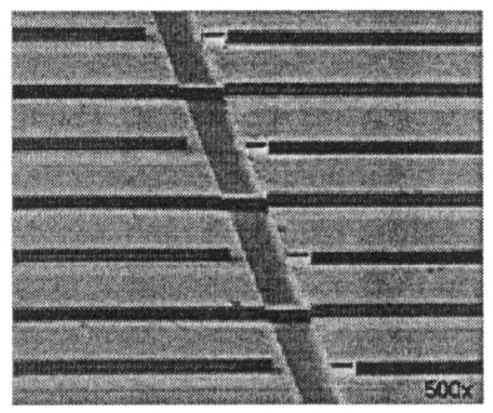

FIGURE 2: SEM image of the grid finger interconnect structure.

\section{PROTOTYPE GaAs MIMs}

The characteristics that make the MIM an attractive solution to the challenges presented by TPV power conversion have the potential to overcome the obstacles to using PV converters with solar dish concentrator systems. Traditionally, one of the difficulties associated with using PV with reflective optics is the relatively large, high-intensity spot size of the illuminated area at the receiver. Monolithic integration offers a solution to that problem. $I^{2} R$ power losses are minimized by fabricating high-voltage, low-current MIM devices. Additionally, the highly efficient BSR, used as a spectral control element in the TPV system, is an effective tool for thermal management in the highintensity solar PV application. The sub-bandgap photons that would have been converted to heat are now reflected out of the power conversion unit in an almost specular fashion. This offers the opportunity to use this portion of the spectrum for other purposes. Finally, the effects of nonuniform illumination may be minimized by choosing a size for the MIM over which the illumination is relatively uniform. The flexibility in the output parameters of the MIM means that the required output voltage may be achieved by a single device that fits within this area of uniform illumination. The fabrication technology developed for the GaInAs on InP-based material system can be readily transferred to the GaAs-based material system, which has bandgaps more appropriate for the terrestrial solar spectrum.

We have fabricated small $\left(0.25-\mathrm{cm}^{2}\right)$ prototype MIMs from GaAs device structures grown on double-side polished $\mathrm{Cr}$-doped semi-insulating $\mathrm{GaAs}$ substrates. Figure 3 shows a cross-sectional schematic of the device structure. It is, in most respects, a typical GaAs double-heterostructure employing GaInP as both the window and back-surface field layers. The exception is the inclusion of a GaAs back-contact layer that provides for lateral current flow between the back-contact grid fingers.

The prototype GaAs MIM is composed of four component cells, using the interconnect structure described above. No attempt has yet been made to optimize the grid design for the anticipated operating conditions in the system. 


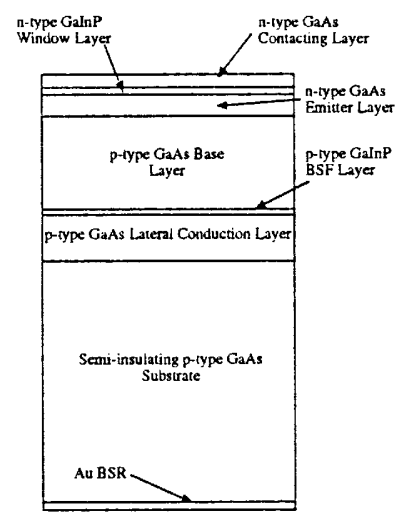

FIGURE 3: Cross-sectional schematic of GaAs device structure used for MIM fabrication.

Figure 4 is a reflectance curve for a $\mathrm{Au} B S R$ on a semi-insulating $\mathrm{Cr}$-doped GaAs substrate. Addition of the thin, active device layers will marginally impact this performance. It is seen that very good performance is obtained for this BSR. For the terrestrial application, $41 \%$ of the incident energy in the direct-normal spectrum has a wavelength greater than $867 \mathrm{~nm}$ (the band edge of GaAs), which may then be used for cogeneration purposes. A typical dish concentrator system may afford between a 400X and 2000X geometric concentration ratio. At a nominal direct-normal insolation of $0.08 \mathrm{watts} / \mathrm{cm}^{2}$ and a concentration ratio of $2000 \mathrm{X}$, there will be 65 watts $/ \mathrm{cm}^{2}$ of incident energy below the response range of the device. This BSR will do an effective job of removing most of this energy from the semiconductor converter and reflecting it to an area where it may be usefully employed.

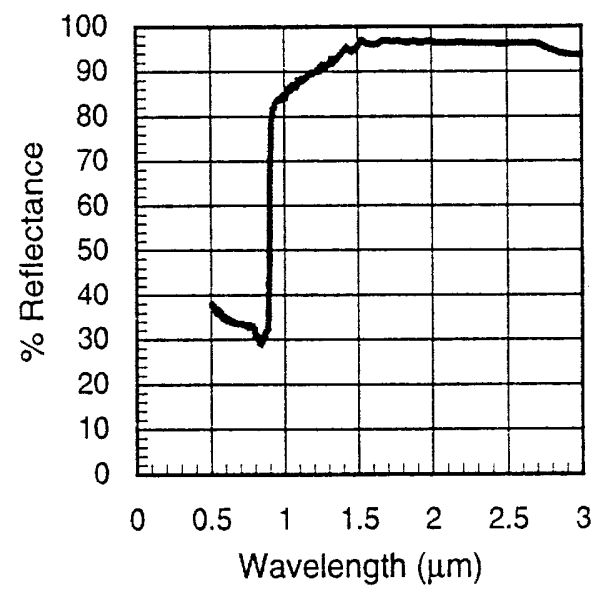

FIGURE 4: Reflectance curve for Au film BSR on semi-insulating GaAs substrate. 
Figure 5 illustrates the current-voltage characteristics of a prototype GaAs MIM under an arbitrarily intense illumination from a flash simulator. Evidence of series resistance due to the nonoptimized grid structure, as well as some shunting, is apparent in the fill factor of $71.8 \%$. A high-quality GaAs device may be expected to generate roughly

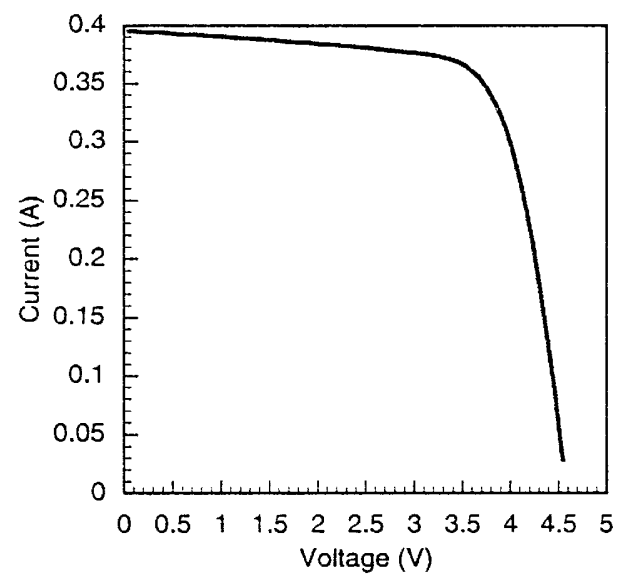

$\mathrm{Voc}=4.585 \mathrm{~V}$
$\mathrm{Isc}=0.3954 \mathrm{~A}$

$\mathrm{V} \max =3.686 \mathrm{~V}$

Fill Factor $=71.85 \%$

$\operatorname{Imax}=0.3535 \mathrm{~A}$

$P \max =1.303 \mathrm{~W}$

FIGURE 5: Current-voltage characteristics of prototype $0.25 \mathrm{~cm}^{2}$, 4-subcell GaAs MIM under a flash simulator with arbitrary intensity.

$24 \mathrm{~mA} / \mathrm{cm}^{2}$ at 1 sun and $1000 \mathrm{~W} / \mathrm{m}^{2}$ and $19.2 \mathrm{~mA} / \mathrm{cm}^{2}$ at $800 \mathrm{watts} / \mathrm{m}^{2}$. The individual cells in the four-cell, $0.25-\mathrm{cm}^{2}$ MIM have an area of $0.0625 \mathrm{~cm}^{2}$. Allowing for a $15 \%$ loss of active area associated with the grid structure and interconnects, the short-circuit current of $0.395 \mathrm{~A}$ represents a current density within the active area of the component cells of $7.45 \mathrm{~A} / \mathrm{cm}^{2}$. This is what one would expect from a geometric concentration ratio of approximately 387X. The power output density of 5.2 watts $/ \mathrm{cm}^{2}$ would represent an efficiency of $16.8 \%$. It should be stressed that no efficiency claim is made here. Rather, it is an indication of how this device would perform under these conditions were the current optimized. There is clearly room for improvement in the fill factors of these devices, and it is reasonable to expect real, measured, efficiencies to exceed $20 \%$ after further development.

\section{MULTIJUNCTION APPROACHES}

The real promise of this technology, however, will be realized with the use of advanced multijunction devices. GaInP/GaAs, two-terminal, two-junction solar cells, invented and developed at NREL, are being produced commercially by several manufacturers for space power applications. These devices have demonstrated efficiencies in excess of $30 \%$ under the direct-normal spectrum, although they have yet to be fully optimized for use in concentrator systems (8). 
The advantage of using a GaInP/GaAs tandem device for this application is not limited to increased efficiency, and hence, power density output. It also offers an advantage related to thermal management. The response range of the tandem device is the same as a single-junction GaAs device because GaAs is the bottom (low-bandgap) component of the tandem. The BSR on a tandem MIM will still reflect back out most of the light with a wavelength above $867 \mathrm{~nm}$. This represents $41 \%$ of the incident energy. The enhanced efficiency over the remaining $59 \%$ of the spectrum means that there will be less abovebandgap energy converted to heat, reducing the load on the cooling systcm required for high-intensity operation. The heat generated by the difference between the energy of the incident photons within the response range of the device and the bandgap is unavoidable and must be managed by a suitable cooling system. Figure 6 is a plot of the photon excess energy as a function of concentration ratio for both the single junction GaAs device and the tandem GaInP/GaAs device. Another advantage of the tandem is that because the spectrum is split between the two component cells, the current density as a function of geometric concentration ratio is effectively halved.

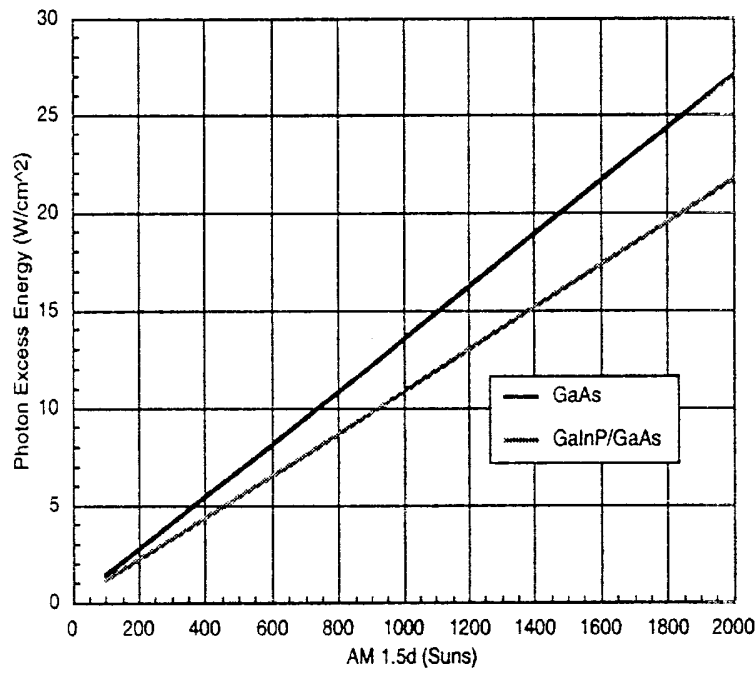

FIGURE 6: Plot of photon excess energy as a function of concentration for both the single junction GaAs case and the tandem GaInP/GaAs case.

Because $I^{2} R$ power losses and thermal management are the key resirains io bis? intensity operation, the tandem device may be expected to operate at significamily lisples. concentration ratios. Work is continuing on adding a third, and ultimate, a fouth jum tion to the GaInP/GaAs tandem cell. Efficiencies in excess of $44 \%$ have ber m pojecice? for a three-junction device using a third junction with a bandgap of $1.10 \mathrm{c}$. $13 \mathrm{esc}$ efficiencies theoretically increase to over $50 \%$ when a low-bandgap (around $0.7 \mathrm{eV}$ ) fourth junction is added (8).

Although a 50\%-efficient power conversion unit composed of ultra-eficion finthe PV devices would be clearly superior to the mechanical alternative, the $30 \%-\mathrm{ct}$. $\mathrm{cm}$ GaInP/GaAs devices that are entering production today would rival the ourpur of the current Stirling engines being used in these systems, while offering a number of arival- 
tages. The primary advantage is the potential for high reliability and low maintenance costs that are characteristic of PV systems when compared to mechanical devices. Another advantage is the significantly reduced mass of the power conversion unit. This has implications for increasing the tracking reliability of the dish and reducing its costs. Added to these advantages is that, in this configuration, fully $41 \%$ of the incident energy is still available for conversion by other means.

\section{ECONOMIC CONSIDERATIONS}

A study done by the Research Triangle Institute (RTI) comparing the cost of energy generated by various concentrator systems identified a required price of $\$ 10 / \mathrm{cm}^{2}$ for tandem-junction GaInP/GaAs devices grown on GaAs substrates (9). This price includes the profit for the manufacturer. The MIM fabrication process is not significantly more complicated than that of a high-quality concentrator cell. There is, however, a requirement for an extra photolithographic step, as well as the deposition of an insulating layer. For this reason, and to make our point, we are conservatively using an estimated price of double that of a standard concentrator cell, or $\$ 20 / \mathrm{cm}^{2}$. A $30 \%$-efficient device operating at $1000 \mathrm{X}$ geometric concentration ratio with a direct-normal insolation of 800 watts $/ \mathrm{m}^{2}$ will have an output power density of 24 watts $/ \mathrm{cm}^{2}$. At a selling price of $\$ 20 /$ $\mathrm{cm}^{2}$, this amounts to $\$ 0.83 /$ watt. This works out to $\$ 20,750$ for tandem PV devices with the potential to generate $25 \mathrm{~kW}$ of electricity. As a point of comparison, the price of a 25 $\mathrm{kW}$ Stirling-engine-based power conversion unit (PCU) is currently around $\$ 180,000$.

The Stirling engine's PCU includes an inverter and power conditioning, as well as any required cooling system. Still, it is clear that within the $\$ 159,250$ difference between the two approaches, adequate funds should be available to pay for these elements in a PV-based PCU. Even the most optimistic projections of future cost reductions for the Stirling- engine-based PCU has them priced at over $\$ 30,000$. It is clear that the dualjunction GaInP/GaAs tandem MIM approach would make PV competitive with these cost projections for Stirling engines. When weight, reliability, and maintenance considerations are factored into the calculations, PV offers a clearly superior conversion technology. Add to these considerations that $41 \%$ of the incident energy is still available for cogeneration in the PV approach, and the PV-based PCU seems even more advantageous.

\section{SUMMARY AND CONCLUSIONS}

Recent advances in high-efficiency III-V solar cells, particularly the GaInP/GaAs tandem cell, combined with a new device configuration developed for TPV applications, make PV a viable alternative to the Stirling-engine-based PCUs used in large dish concentrator systems. Potential advantages to using PV for this application include reduced price, reduced mass, reduced maintenance costs, increased reliability, and the ability to use $41 \%$ of the incident radiation for cogeneration purposes. The economics of this 
application, with its focus on efficiency, become a strong motivation for continued development of high-efficiency multijunction device technology.

Prototype monolithic interconnected modules, using GaAs device structures, have been fabricated and characterized. The performance of a back-surface reflector on a semi-insulating GaAs substrate has been investigated. Future work will include the fabrication of larger-area MIMs using GaInP/GaAs tandem devices and optimized grid structures, as well as on-sun testing of these devices using NREL's solar furnace.

In the decade since the use of PV in high concentration systems using reflective optics has been seriously analyzed as part of the DOE's PV program, significant advances have been made in all of the component technologies. High-efficiency multijunction PV devices are entering production for space power systems. New device configurations promise to overcome the old problems of $I^{2} \mathrm{R}$ power losses, packing fractions and IR heating. Advances in reflective optics and active cooling systems have also continued at an impressive pace. Clearly, formidable challenges present themselves when envisioning using solid state devices to generate power in the extreme environment of $1000 \mathrm{X}$ and beyond. Just as clearly, these challenges are likely to be met by the sustained efforts of the community, given a sufficient commitment of resources and time.

\section{ACKNOWLEDGEMENTS}

The authors wish to thank Dan Friedman and Charlene Kramer of NREL's HighEfficiency III-V Team for supplying the GaAs device structures. They would also like to thank Mark Wanlass and Jeff Carapella of NREL's TPV Team and Chris Murray and his team at Bettis APL for their efforts in developing the MIM technology. The efforts of Keith Emery and Tom Moriarty of NREL's Characterization Team are also gratefully acknowledged.

\section{REFERENCES}

1. Annual Book of ASTM Standards, Volume 14.02, 1987, page 470.

2. Sater, B. L., and Goradia, C., Proceedings 11 th Photovoltaics Specialists Conference, p. 356, 1975.

3. Bordon, B. G., "A Monolithic Series-Connected AlGaAs/GaAs Solar Cell Array," Proceedings 14th Photovoltaics Specialists Conference, pp. 554-562, 1980.

4. Wojtezuk, S., Parados, and Walker, G., "P/N In(Al)GaAs Multijunction Laser Power Converters," in Proceedings of XIII Space Photovoltaic Research and Technology Conf., pp. 363-371, 1994.

5. Wilt, D. M., et al., "Monolithically Interconnected InGaAs TPV Module Development," Proceedings 25th Photovoltaic Specialists Conference, pp. 43, 1996.

6. Scott-Monk, J., Proceedings 13th Photovoltaic Specialists Conference, pp. 421, 1978.

7. Ward, J. S. et al., "A Novel Design for Monolithically Interconnected Modules for Thermophotovoltaic Power Conversion," in Third NREL Conference on Thermophotovoltaic Generation of Electricity, pp. 227-236, 1997.

8. Kurtz, S. R., Myers, D., and Olsen, J. M., Proceedings 26th Photovoltaic Specialists Conference, pp. $875,1997$.

9. 'Whisnant, R. A., Hutchby, J. A., Timmons, M. L., Venkatasubramanian, R., Hills, J. S., First World Conference on Photovoltaic Energy Conversion, pp. 1103, 1994. 